
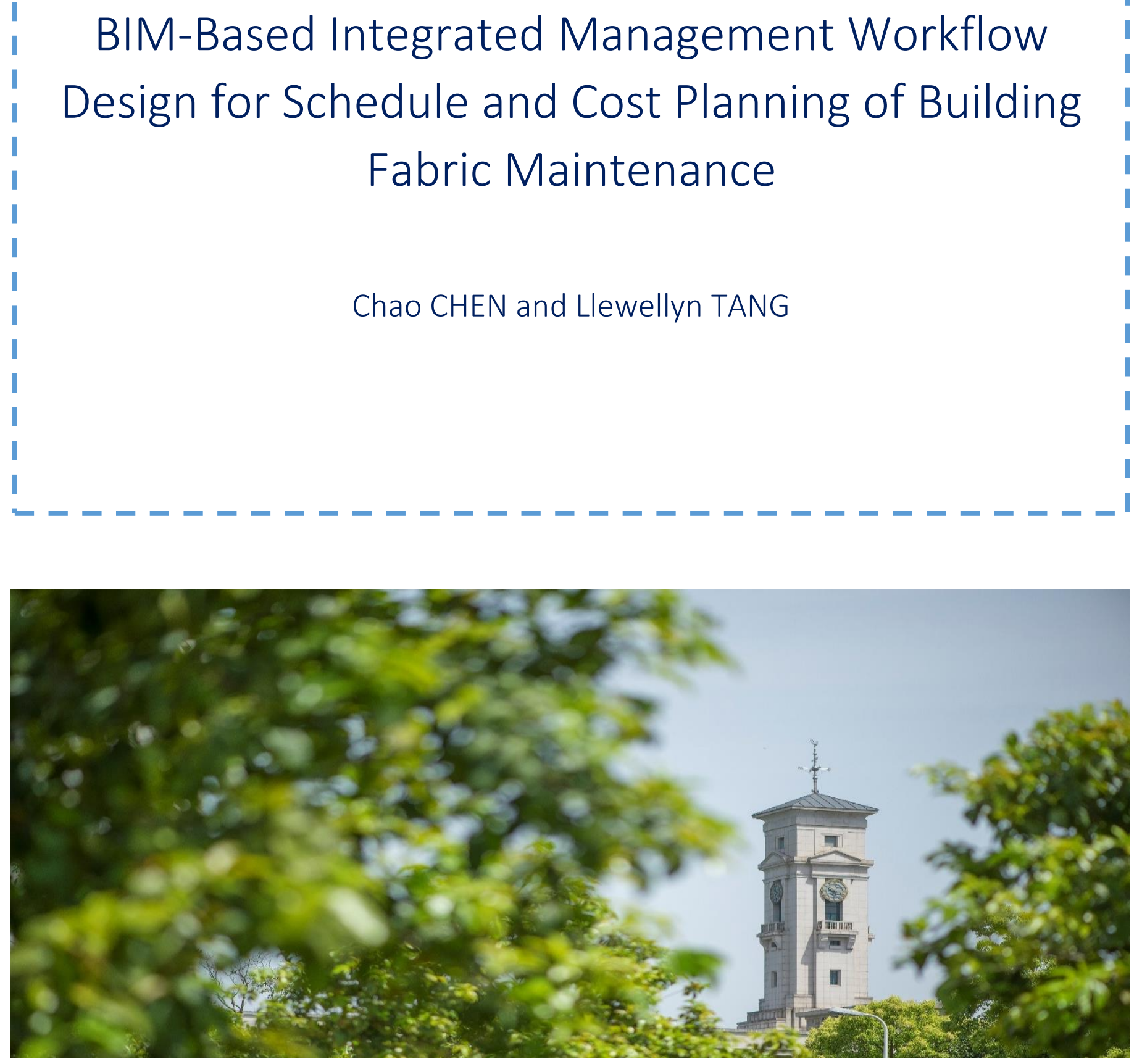
University of Nottingham Ningbo China, 199 Taikang East Road, Ningbo, 315100, Zhejiang, China.

First published 2019

This work is made available under the terms of the Creative Commons Attribution 4.0 International License:

http://creativecommons.org/licenses/by/4.0

The work is licenced to the University of Nottingham Ningbo China under the Global University Publication Licence:

https://www.nottingham.edu.cn/en/library/documents/researchsupport/global-university-publications-licence.pdf 


\title{
BIM-Based Integrated Management Workflow Design for Schedule and Cost Planning of Building Fabric Maintenance
}

\author{
Chao CHEN ${ }^{a}$ and Llewellyn TANG \\ a University of Nottingham Ningbo China, 199 Taikang East Road, University Park, Ningbo \\ 315100, China \\ b University of Hong Kong, Hong Kong, China
}

\begin{abstract}
The operation and maintenance (O\&M) is the longest and costliest phase during the entire building lifecycle. In recent decades, with the rapidly increasing costs of new constructions, the effective maintenance has become more important to the existing buildings, particularly to their fabric components, which include both architectural and structural items for maintaining physical characteristics and ensuring the normal performance of the existing building over its lifecycle. However, building maintenance costs are also increasing dramatically and this situation mainly results from the delay of maintenance work due to inefficient maintenance planning for the facility management purpose. The inefficient maintenance planning is caused due to a lack of effective methods and techniques for predicting the uncertainties, including schedule and costs during the maintenance stage. Therefore, this paper proposes an innovative management workflow design which integrates Building Information Modelling (BIM) with digital programming to implement an efficient schedule and cost planning of building fabric maintenance. Through this BIM-based workflow design, the knowledge gap between maintenance theories and practical maintenance management can be narrowed by a consistent and sustainable building information flow, which is highly linked with the design and construction phase. This study contributes to integrating the traditional maintenance management with digital technologies to improve the management performance and maintenance efficiency of the O\&M phase in the future.
\end{abstract}

Keywords: Building Information Modelling (BIM); Management workflow; Building fabric maintenance; Cost and schedule planning; Digital programming. 


\section{Introduction}

A building lifecycle consists of several phases including planning, design, construction, operation and maintenance $(\mathrm{O} \& \mathrm{M})$, and even demolition. Compared with other phases, O\&M requires the project owners to spend the longest time and the most costs on it [1]. For high performance of buildings, maintenance should be considered seriously as its management plays a major role in the performance of facilities [2]. In recent decades, with the dramatically increasing costs of new constructions, the effective maintenance management has become more important to the existing buildings, particularly to their fabric components, which include both architectural and structural items for maintaining physical characteristics and ensuring optimal performance of the existing building over its lifecycle [3, 4]. However, due to lack of efficient methods and techniques for building maintenance management, it becomes difficult to building owners and users to efficiently plan the maintenance work schedule and accurately estimating the maintenance costs, which are increasing rapidly due to the delay of maintenance work [5-7]. Such a delay is caused by uncertainties that are not effectively predicted during the maintenance stage due to different factors such as budget limitations, environmental conditions, lack of communications, the availability of skilled labors, inclement weather and climate, etc. [3, 8-10]. These factors can also highly influence the cost performance and management efficiency of the building design and construction phase [11-14]. That means there is a close link between the maintenance stage with the design and construction phase. Therefore, if the building fabric maintenance can be related prior to the early stage of the design and construction phase, the fabric maintenance schedules can be planned in advance and the fabric maintenance costs can be minimized through effective predictions of the uncertainties.

As this study mainly focuses on the building fabric maintenance, the uncertainties related to such maintenance involve the geometric information of fabric component items, the prices of items, the locations of items, labor costs, inspection fees, etc. The collections and determinations of this information can help implement successful maintenance work within optimal schedules and minimum costs. To achieve this aim, a promising digital technology named Building Information Modelling (BIM) is adopted in this study. BIM not only can 
realize three-dimensional (3D) geometric representations of building fabric components but also can provide detailed information of fabric characteristics to help to build owners and users make construction or maintenance plans [15]. Although currently BIM is pervasively used in the building design and construction phase to improve design efficiency and construction productivity, it will be widely applied into the O\&M phase for building maintenance management $[16,17]$.

Therefore, as the first research objective in this study, an innovative management workflow is designed based on the integration of BIM with digital programming to help owners and users make efficient planning for schedule simulations and cost estimations of the building fabric maintenance work in compliance. Secondly, through this workflow design, BIM models developed during the design and construction phase can be extended to maintain a consistent and sustainable information flow for narrowing the knowledge gap between the theories and practical applications of building fabric maintenance management. Furthermore, a typical case study in China is also introduced to preliminarily validate the feasibility of this management workflow design in practice through a digital panel prototype, which is developed based on the workflow mechanism.

\section{Literature Review}

\subsection{Building Fabric Maintenance}

According to British Standard " 3811 ", the building maintenance can be defined as a combination of any actions carried out to retain or restore a building item into an acceptable condition for the purpose of building normal performance [18]. As shown in Fig.1, the building maintenance currently can be categorized into five types as following $[3,7,19,20]$ :

- Preventive maintenance: It is planned to prevent the breakdowns of items according to personnel's experience. Preventive maintenance is conducted to keep a building operating in normal performance through regular inspection and repair including painting, covering work, etc.

- Corrective maintenance: This maintenance type is unplanned. It refers to urgent repair or 
replacement of a building item that cannot perform its required function any more due to delay or failure of preventive maintenance.

- Service maintenance: It includes maintenance items that are not requested with urgent actions by owners and users.

- Condition-based maintenance: It utilizes the changes in the conditions or performance of items as the main reason to carry out maintenance work. Usually, it is planned by scheduled monitoring of the items.

- Deferred maintenance: When the necessary maintenance is put off without a determined schedule, it is named deferred maintenance. This maintenance is delayed due to various factors such as budget limitations, the availability of skilled labors, inclement weather and climate, etc.

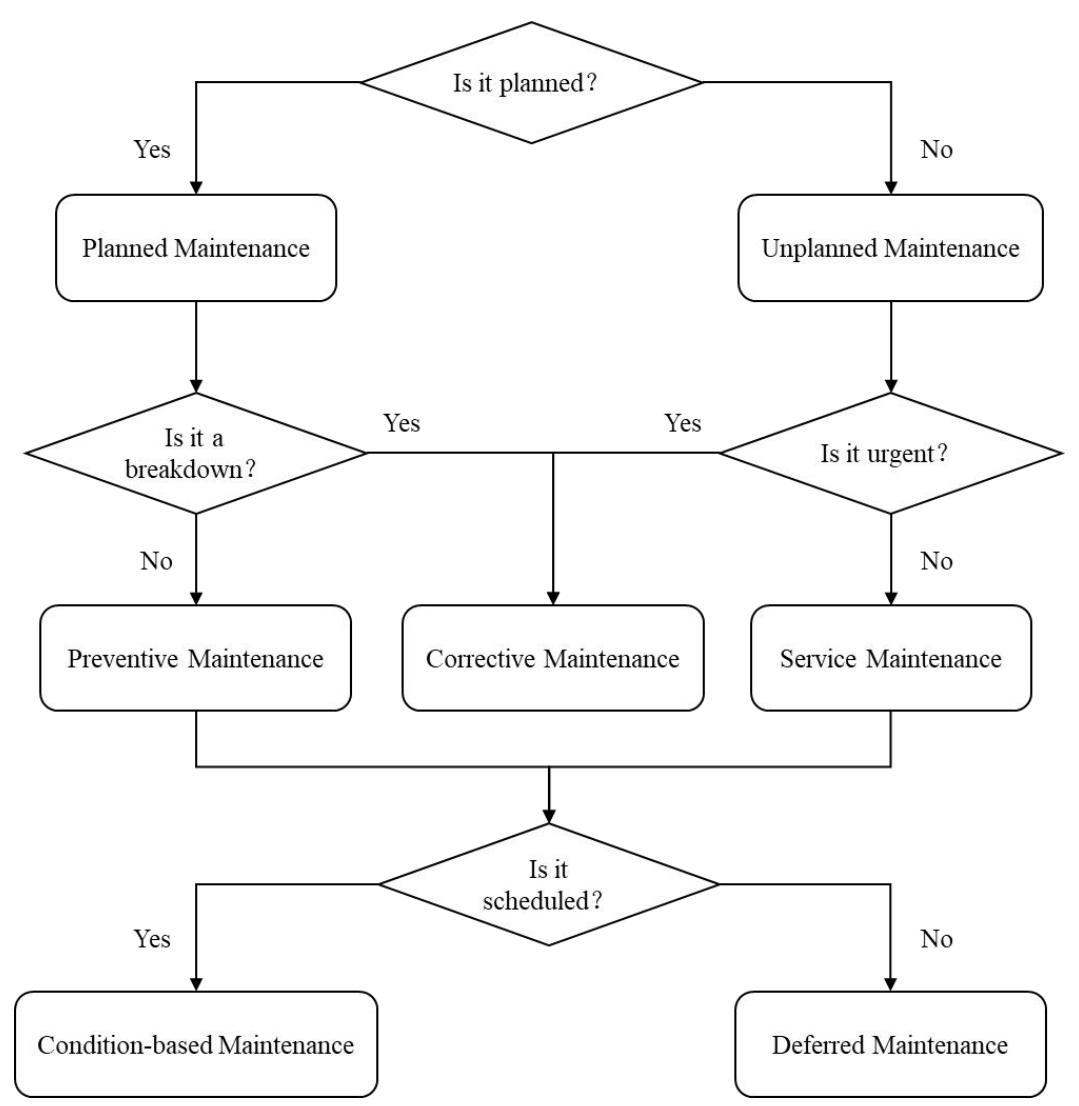

Fig.1. Types of Building Maintenance

Building fabric components include both architectural and structural items of a building to ensure its stable physical characteristics and normal operation performance for occupants to stay inside 
$[21,22]$. Compared with the maintenance of mechanical, electrical and plumbing (MEP) systems in the building, the maintenance work for its fabric components usually is more difficult. Because the conditions of the fabric components cannot be monitored with real-time data given back through sensors that are usually applied into MEP systems [23]. Regular inspections and faulty detections conducted by experienced personnel are still the main methods used in fabric maintenance management to determine the item and its maintenance type [21, 24, 25]. However, in recent decades, the maintenance costs of existing buildings are increasing rapidly [26]. It is reported by Al-Hajj and Horner that $30 \%$ to $40 \%$ of the items contribute to $80 \%$ to $90 \%$ of the

maintenance costs [27]. The result means significant costs are focused on a few numbers of building items due to inefficient management. In addition, the yearly costs of individual building maintenance have been predicted to exceed the initial cost of construction by $10 \%$ [28]. Therefore, to improve the efficiency of fabric maintenance management and minimize the maintenance costs, optimal planning of schedule and costs for maintenance work should be implemented in time $[5$, 26].

\subsection{Building Information Modelling (BIM) for Project Management}

BIM has become one of the most promising technologies for architectural, engineering and construction (AEC) projects in recent years due to the benefits it can bring an accurate $3 \mathrm{D}$ modelling, integrated collaboration and consistent information flow throughout the building lifecycle [15]. A multi-dimensional (n-D) BIM concept even has been proposed for implementing schedule simulation, cost estimation and maintenance execution to realize the value of digital information management in practice [29].

In this n-D BIM concept, the geometric information and semantic relationships between building items are represented in 3D digital modelling, which is defined as the basic 3D BIM applied into the modern design phase rather than traditional Computer-Aided Design (CAD) [30]. However, in the AEC projects, only using 3D modelling information is too far away from the real construction phase, which highly depends on time and budget [31]. That is why a concept of four-dimensional (4D) BIM, which integrates schedule (duration) simulation with 3D modelling, is developed to link the construction management with the design phase 
in practice [32]. Nevertheless, 4D BIM cannot be used to estimate and manage cost performance during the construction phase [16]. As the cost performance is quite important to the successful implementation of building construction process, five-dimensional (5D) BIM is proposed to integrate the 4D BIM with cost estimations to improve the construction management efficiency and cost performance [33]. Here the cost estimations are implemented based on digital quantity surveying and economic forecast of other production factors such as labors, logistics, market rates, etc. In fact, 5D BIM not only can bring the cost benefits for the design and construction phase but also can be applied into the facility management (FM) during the project O\&M phase [34, 35]. Furthermore, to meet the increasing demands and requirements of FM, a concept of six-dimensional (6D) BIM, which aims to integrate the conventional FM pattern with 5D BIM in compliance, also has been proposed to provide digital schedule and cost management for the later stage of the project lifecycle $[35,36]$.

\subsection{Linking BIM with Building Fabric Maintenance}

Although the n-D BIM concept shows great potential in organizing and utilizing valuable information from each project stage to implement efficient and sustainable building lifecycle management, knowledge gaps and limitations are still existing between practice and the theory at present. Many types of researches has been conducted to investigate the feasibility and values of BIM applications on project management, as shown in Table 1. However, each research has certain limitations and only a few pieces of researches focus on the use of BIM in the O\&M phase. Moreover, currently, there is even no relevant study investigating the BIM application on building fabric maintenance.

Table 1. Researches on BIM-Based Project Management

\begin{tabular}{|l|l|l|}
\hline Authors/Year & Topic & Research Limitations \\
\hline $\begin{array}{l}\text { Olatunji et al. (2010) } \\
{[37]}\end{array}$ & $\begin{array}{l}\text { Building Information Modelling } \\
\text { and Quantity Surveying Practice }\end{array}$ & $\begin{array}{l}\text { exploration of BIM-based quantity } \\
\text { measurement in the project design } \\
\text { and construction phase, not } \\
\text { considering the later O\&M } \\
\text { phase }\end{array}$ \\
\hline
\end{tabular}




\begin{tabular}{|c|c|c|}
\hline $\begin{array}{l}\text { Mitchell (2012) } \\
\text { [33] }\end{array}$ & $\begin{array}{l}\text { 5D - Creating Cost Certainty and } \\
\text { Better Buildings }\end{array}$ & $\begin{array}{l}\text { application of } 5 \mathrm{D} \text { BIM to only the } \\
\text { design and construction phase } \\
\text { with the goal of delivering better } \\
\text { buildings with cost certainty }\end{array}$ \\
\hline $\begin{array}{l}\text { Frei et al. (2013) } \\
\text { [38] }\end{array}$ & $\begin{array}{l}\text { Critical success factors, } \\
\text { opportunities and threats of the cost } \\
\text { management profession: the case of } \\
\text { Australasian quantity surveying } \\
\text { firms }\end{array}$ & $\begin{array}{l}\text { combined emerging technologies } \\
\text { with factor analysis to achieve } \\
\text { efficient cost management for } \\
\text { sustained growth and } \\
\text { competitiveness of quantity } \\
\text { surveying professions, not specific } \\
\text { to the maintenance purpose }\end{array}$ \\
\hline $\begin{array}{l}\text { Smith (2016) } \\
\text { [39] }\end{array}$ & $\begin{array}{l}\text { Project Cost Management with 5D } \\
\text { BIM }\end{array}$ & $\begin{array}{l}\text { investigated the quality and } \\
\text { comprehensiveness of 5D BIM } \\
\text { model in project cost management } \\
\text { for commercial strategy making, } \\
\text { without details of practical } \\
\text { applications or case studies for } \\
\text { validation }\end{array}$ \\
\hline $\begin{array}{l}\text { Lu et al. (2016) } \\
{[40]}\end{array}$ & $\begin{array}{l}\text { A financial decision-making } \\
\text { framework for construction projects } \\
\text { based on 5D Building Information } \\
\text { Modeling (BIM) }\end{array}$ & $\begin{array}{l}\text { estimated 5D BIM-based Cash } \\
\text { flow by considering the project } \\
\text { and contract types in order to make } \\
\text { a better project financing plan for } \\
\text { contractors, less knowledge about } \\
\text { the technical development of } \\
\text { existing BIM tools for } \\
\text { maintenance purpose }\end{array}$ \\
\hline $\begin{array}{l}\text { Kehily \& Underwood } \\
(2017) \\
{[16]}\end{array}$ & $\begin{array}{l}\text { Embedding Life Cycle Costing in } \\
5 \mathrm{D} \text { BIM }\end{array}$ & $\begin{array}{l}\text { integrated 5D BIM with Life Cycle } \\
\text { Costing functionality by } \\
\text { developing a spreadsheet } \\
\text { calculation structure based on an } \\
\text { existing BIM tool without } \\
\text { extension for detailed } \\
\text { maintenance analysis }\end{array}$ \\
\hline $\begin{array}{l}\text { Pučko et al. (2017) } \\
\text { [41] }\end{array}$ & $\begin{array}{l}\text { Application of 6D Building } \\
\text { Information Model (6D BIM) for } \\
\text { Business-storage Building in } \\
\text { Slovenia }\end{array}$ & $\begin{array}{l}\text { an insight of 6D BIM for the } \\
\text { execution of maintenance works } \\
\text { throughout the building lifecycle, } \\
\text { but only for building system } \\
\text { maintenance, not for fabric } \\
\text { maintenance }\end{array}$ \\
\hline $\begin{array}{l}\text { Lu et al. (2018) } \\
\text { [42] }\end{array}$ & $\begin{array}{l}\text { Activity theory-based analysis of } \\
\text { BIM implementation in building } \\
\text { O\&M and first response }\end{array}$ & $\begin{array}{l}\text { provided a comparative analysis } \\
\text { based on the activity theory to } \\
\text { facilitate the implementation of } \\
\text { BIM in building O\&M; however it }\end{array}$ \\
\hline
\end{tabular}




\begin{tabular}{|l|l|l|}
\hline & & $\begin{array}{l}\text { still stayed on a theoretical } \\
\text { model that used data from } \\
\text { survey and interview with } \\
\text { sample size risk }\end{array}$ \\
\hline
\end{tabular}

Therefore, in order to narrow the knowledge gap between the BIM theory and building maintenance practice, particularly in the blank area of building fabric maintenance management, this study aims to design an innovative management workflow that integrates BIM with digital programming for schedule and cost planning of building fabric maintenance. This designed workflow not only links the n-D BIM concept with building fabric maintenance knowledge to efficiently achieve schedule simulations and cost estimations of maintenance work, but also clarifies a detailed mechanism for developing a digital management panel prototype, which can help building owners and users efficiently manage the maintenance work plan and easily evaluate the work performance in practice.

\section{Methodology}

The methodology of this study is shown in Fig.2. After determining the building fabric maintenance items and corresponding maintenance types, a multi-dimensional BIM model of the building can be created based on an integration of 3D geometric representations with schedule simulations and cost estimations, which depend on component materials, quantity take-off, labor costs (including equipment and logistics costs), etc. In addition, a classic analysis method named Weibull Distribution is also adopted in the methodology to simplify parametric analysis for building fabric maintenance and predict reliable planning of schedule and costs for maintenance management [43, 44]. The analysis formulas of Weibull Distribution then is encoded as computer-based functions through digital programming in which specific computer languages are used. Furthermore, an appropriate data format is also required for the workflow design in order to realize building information consistency between the design and construction phase with the O\&M phase.

When the BIM-based workflow design is completed, the next step is to produce a digital 
management panel based on it for building owners and users to check the maintenance performance and calculate the planned schedule and costs according to the determined fabric maintenance items. To preliminarily validate the feasibility of the workflow design and digital management panel, a case study of an existing building in China is applied to achieve this purpose. Here sensitivity analysis is adopted to determine whether the BIM-based schedule and cost planning brings economic benefits for the maintenance stage [45]. If the answer is positive, then the feasibility of the workflow design is preliminarily validated and it can be applied into the practice of the case; if it is negative, the maintenance schedule and costs require replanning by checking the details of the workflow design and the input data.

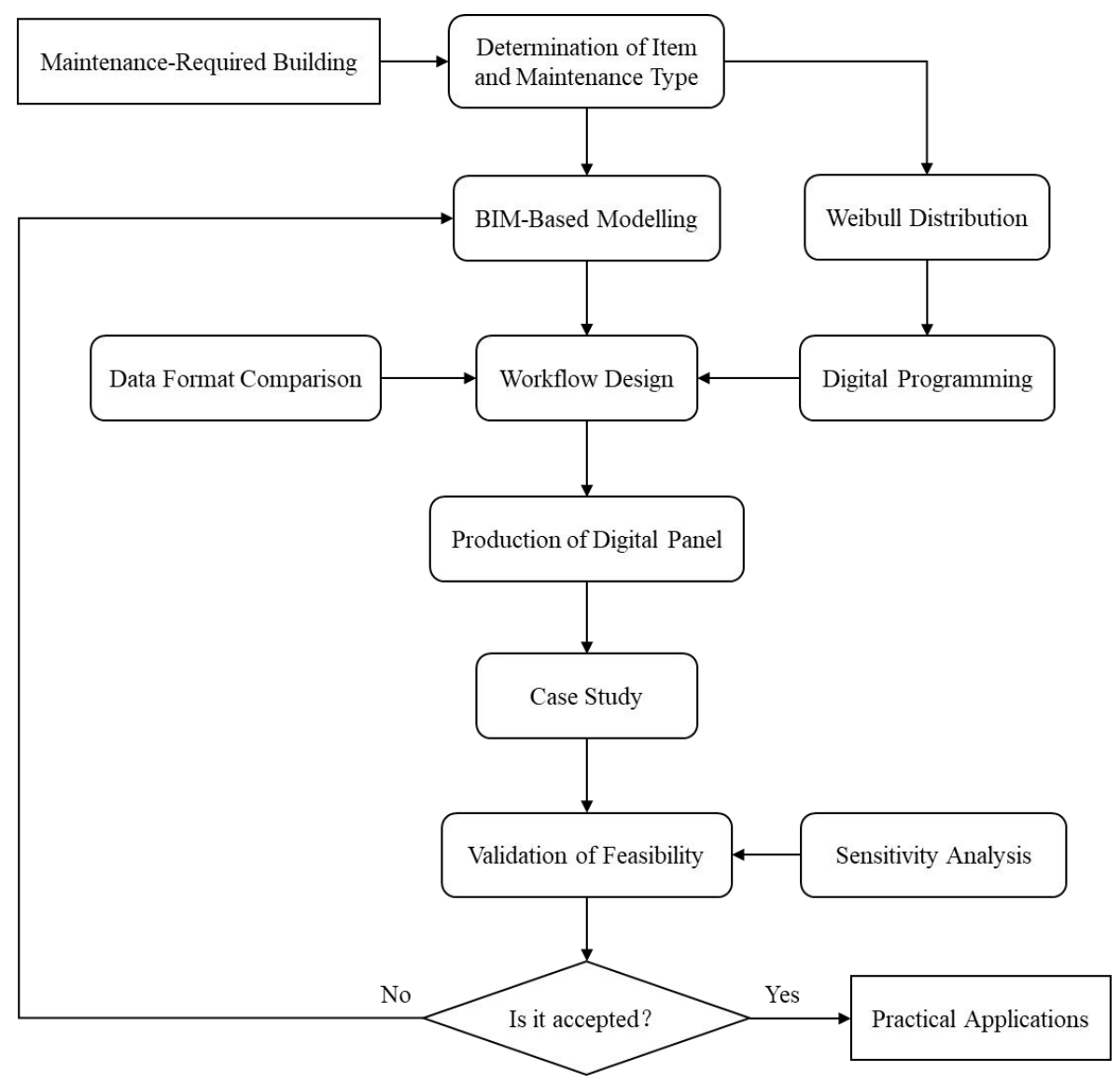

Fig.2. Methodology of the Study

As the most popular and reliable analysis method with small sample sizes and high flexibility, Weibull Distribution can be used to determine the key information about preventive and corrective maintenance particularly for building fabric components [43]. The Weibull probability density function can be varied under different maintenance conditions depending on the value of the shape 
parameter, which decides the shape of the distribution [46]. This parameter can determine the most appropriate distribution for the analysis of building fabric maintenance. Because the preventive maintenance (PM) is planned before the breakdowns of fabric components, it is quite important to determine the optimum preventive maintenance intervals for the schedule planning of maintenance work. This interval can be determined by using the following formula [47]:

$$
T=m \theta+\delta
$$

Where $T$ is the optimum preventive maintenance interval, $m$ is a function of the ratio of the corrective maintenance $(\mathrm{CM})$ cost to the PM cost, which can be determined from a reference table by using the ratio and the shape parameter $\beta, \theta$ is the scale parameter of the Weibull Distribution and $\delta$ is the location parameter of Weibull Distribution. The determined interval can highly influence the cost per unit time, which is a key indicator for the cost planning of fabric maintenance. Its calculation formula is shown as below $[5,48]$ :

$$
C P U T=\frac{c_{p} R(t)+c_{f}[1-R(t)]}{T R(t)+\int_{0}^{t} t f(t) d t}
$$

Where CPUT is the cost per unit time, $R(t)$ is the reliability function, $c_{p}$ is the preventive maintenance cost, $c_{f}$ is the corrective maintenance cost, $t$ is the usability time of the fabric component and $f(t)$ is the probability density function for the Weibull Distribution. The reliability function for the building fabric maintenance can be determined from the following formula [48]:

$$
\begin{gathered}
R(t)=\int_{t}^{\infty} f(t) d t \\
1-R(t)=\int_{0}^{t} f(t) d t
\end{gathered}
$$


Additionally, an expected replacement cycle length for corrective maintenance work after breakdowns of fabric components also can be determined by using the formula as below [49]:

$$
M(t)=\frac{\int_{-\infty}^{t} t f(t) d t}{1-R(t)}
$$

Where $M(t)$ is the mean of expected replacement cycle length for corrective maintenance work after breakdowns of building fabric components.

Furthermore, there are several specific equations used for calculating fabric maintenance costs in this study. The first formula is used to determine the CM cost of building fabric components:

Take-off quantity $\times$ Unit rate + Labor cost $=$ Corrective maintenance cost

Where the unit rates of fabric components and the labor costs highly depend on the conditions of local construction markets. Usually, an average ratio of PM cost to CM cost for electrical and mechanical systems is around 0.35 [50]. As the PM cost for fabric components is lower than that for MEP systems due to the complexity of the latter, an average value of 0.25 (mean of the lowest and the highest ratios), which is smaller than the average ratio of MEP maintenance, then is assumed to be a general ratio of PM cost to $\mathrm{CM}$ cost for building fabric maintenance in this study [51]. Therefore, the PM cost for fabric components can be determined by:

$0.25 \times$ Corrective maintenance cost $=$ Preventive maintenance cost

Moreover, the inspection cost (IC) usually accounts for $80 \%$ of the PM cost according to empirical assessment [51]. Therefore the inspection cost of building fabric components can be assumed as follows: 
In order to intuitively validate the feasibility of the schedule and cost planning which is obtained from the management panel based on this workflow design, sensitivity analysis is an appropriate method to achieve this purpose by linking the building fabric maintenance with its sensitive uncertainties such as the limitations of budget, the fluctuations of material prices, the availability of skilled labors and equipment, etc. [52]. These uncertainties also can influence the schedule and cost performance of the design and construction process. This is why it is necessary to consider the maintenance management at the early stages of the design and construction phase to improve the schedule and cost performance [6].

For the assessment based on sensitivity analysis, there are several economic benefit indicators including net benefits, internal rate of returns, benefit-cost $(B / C)$ ratios, etc. [51]. In this study, there are two reasons for choosing the $\mathrm{B} / \mathrm{C}$ ratio as the key indicator for the assessment of the planning. The first reason is that decision-makers are usually interested in how to maximize the return of maintenance investment through the comparison of costs with benefits. Sensitivity analysis provides an appropriate resolution to settle down this issue [53]. Another reason of choosing $\mathrm{B} / \mathrm{C}$ ratio as the key indicator is that $\mathrm{PM}$ can be assessed as a benefit from the maintenance investment and become more intuitive to perception through this ratio. There are two main parameters that can influence the $\mathrm{B} / \mathrm{C}$ ratios. One is the probability of detection (POD) of potential failure $(\alpha \in[0,1])$ and the other is the potential to functional failure likelihood $(\beta \in[0,1])$. The correlation between the $\mathrm{B} / \mathrm{C}$ ratios and these two parameters can be expressed in the following formula [51]:

$$
B / C=\frac{B_{P M}}{C_{P M}}=\frac{\alpha \beta \bar{C}_{F}}{\bar{C}_{I}+\alpha \bar{C}_{R}}
$$

Where $B_{P M}$ is the benefit of preventive maintenance, $C_{P M}$ is the overall cost of preventive 
maintenance, $\bar{C}_{F}$ is the mean replacement cost for corrective maintenance after the occurrence of breakdowns, $\bar{C}_{I}$ is the mean cost of the inspection, and $\bar{C}_{R}$ is the mean repair cost of preventive maintenance. Only when the $\mathrm{B} / \mathrm{C}$ ratio is larger than 1 , it means the benefit will exceed the cost if the schedule and cost planning is implemented in the case. Therefore, the validation result of the feasibility is positive and the workflow design can be accepted for the practical application of the case study.

\section{Workflow design}

Before the management workflow design, it is essential to determine the answers of the former three steps according to the methodology of this study: what BIM tools would be used for modelling, what data format would be used for interoperation and what digital languages would be used for programming.

For the BIM modelling, Revit was chosen in this study due to considering its wide applications and comprehensive abilities in 3D representations of building geometric and semantic information. Nevertheless, to achieve the requirements of 4D and even 5D BIM, only using Revit is not possible. Therefore, we selected some well-known 4D and 5D BIM software that is widely used in the global AEC market for integrations with Revit 3D modelling. Through comparing them based on the standard criteria of defined 4D and 5D BIM as shown in Table $2[34,39,40]$, the Vico Office, which is a powerful 5D BIM software developed by Trimble, was chosen for BIM-based modelling and secondary development purpose [54].

Table 2. Comparison of Multiple Software for 4D and 5D BIM Applications

\begin{tabular}{|c|c|c|c|c|c|}
\hline Software & $\begin{array}{c}\text { Revit }+ \\
\text { MS Project }\end{array}$ & Synchro & $\begin{array}{c}\text { Glodon } \\
\text { BIM5D }\end{array}$ & $\begin{array}{c}\text { iTWO 4.0 } \\
\text { 5D BIM }\end{array}$ & Vico Office \\
\hline 3D modelling & Yes & Yes & Yes & Yes & Yes \\
\hline
\end{tabular}




\begin{tabular}{|c|c|c|c|c|c|}
\hline Take-off quantity & Yes & No & Yes & Yes & Yes \\
\hline Task Schedule & Yes & Yes & Yes & Yes & Yes \\
\hline Resource allocation & No & Yes & Yes & Yes & Yes \\
\hline 4D simulation & No & Yes & Yes & Yes & Yes \\
\hline Risk analysis & No & Yes & No & Weak & Yes \\
\hline Quantity cost estimation & Yes & No & Yes & Yes & Yes \\
\hline Overall cost estimation & Rough & Rough & Yes & Yes & Yes \\
\hline Secondary development & Yes & No & No & No & Yes \\
\hline
\end{tabular}

When the modelling step is finished, sustainable information flow should be implemented to ensure high data interoperability between different BIM software and meanwhile keep the information consistency between the maintenance stage with the design and construction phase. This implementation depends on a uniform data format. Therefore, an official ISO data format named Industry Foundation Classes (IFC) was adopted in this study after a performance comparison of different data formats, as shown in Table 3 [55]. It supports integrations of heterogeneous data from various BIM software to implement a consistent and sustainable information flow throughout building lifecycle [56].

Table 3. Performance Comparison of Multiple Software for 4D and 5D BIM

\begin{tabular}{|l|l|l|l|l|}
\hline & $\begin{array}{l}\text { Geometric } \\
\text { Information }\end{array}$ & Semantic & Spatial & Level of Details \\
\hline IFC & Parametric; & Object support & Engineering; & Level 0 - 5 \\
\hline CityGML & BRep-boundary; Tessellation & & Geodetic & \\
\hline DXF/DWG & BRep-boundary; & Object support & Engineering; & Level $0-1$ \\
& Tessellation & & Geodetic & \\
\hline COLLADA & BRep-boundary; & None or simple & Engineering & N/A \\
& Tessellation & Object support & Engineering; & User defined \\
\hline
\end{tabular}




\begin{tabular}{|l|l|l|l|l|}
\hline X3D & $\begin{array}{l}\text { BRep-boundary; } \\
\text { Tessellation }\end{array}$ & None & $\begin{array}{l}\text { Engineering; } \\
\text { Geodetic }\end{array}$ & User defined \\
\hline SVG & Only line and area & None & $\begin{array}{l}\text { Engineering; } \\
\text { Geodetic }\end{array}$ & User-defined \\
\hline KML & BRep-boundary & Only geodetic & Geodetic & User-defined \\
\hline
\end{tabular}

IFC is also proposed to realize an interoperable data flow for BIM-based integrated web services as mentioned in the maturity model of BIM Level $3[57,58]$. To organically integrate the information of building fabric maintenance with the BIM-based interoperable data flow, specific programming languages are required particularly for the design of computing functions and database services. In this study, a Web SQL (Structured Query Language) database was used for efficient data storage [59]. This database is designed as an SQLite according to the encoding specification of HTML5, which is a standard mark-up language for structural descriptions of a functional web page [60]. Furthermore, HTML5 supports direct access to the SQL database without using a web server [61]. This can highly improve the efficiency of data access and processing including entry, exchange and extraction. In addition, the JavaScript, which is a high-level interpreted programming language, was also applied to implement the executions of computing functions and the interactions with the database [62]. The JavaScript-based digital programming can be embedded into the HTML5 documents for owners and users to determine and check the key information about the building fabric maintenance. This is why a digital management panel is also designed based on the workflow to make use of it in practice.

The management workflow is designed as shown in Fig.3. This design was inspired by the fundamental concept of using integrated web services, which also can be called "BIM Hub" to link the kernel database with the project lifecycle management (PLM) platform for implementing sustainable management during the phase of BIM Level 3 [57]. Therefore, this workflow design can be understood as practical implementation and extension of the BIM 
Level 3 concept for realizing its value not only in the design and construction phase but also in the maintenance stage.

The workflow is designed into three steps. The first step is a preparation step, which aims to determine the basic information of building fabric components including geometric data, semantic information, quantity take-off, properties of materials and spatial locations. Such information can be obtained from 3D BIM models provided by Revit and 5D BIM estimations conducted in Vico Office. Furthermore, other detailed information such as unit rates, which is understood as the prices of unit components, can be determined from the Web SQL database. It should be noticed that all the information initially was only used for deepening design and quantity surveying purposes during the design and construction phase.

The second step is an execution step. This step integrates the take-off quantity information from IFC files with the data like unit rate extracted from the SQL database through a JavaScript-based Application Programming Interface (API), which allows users to access the database and execute relevant operations such as query and extract. Also, it is applicable to use the JavaScript to encode functions based on the calculation formulas for Weibull Distribution, quantity take-off and determination of multiple maintenance costs.

By using the relevant equations and formulas mentioned in the methodology section, specific data outputs such as TQ-based cost and PM cost then can be automatically calculated by invoking those formula functions. Such automatic data calculations are much faster and more accurate than manual calculations. Meanwhile, labor and time costs on complex calculations can be highly reduced through JavaScript-based programming. Furthermore, an extra API is also provided to support the geometric data interaction between the IFC files and OBJ files (a file format of 3D modelling), in order to realize 3D representations of BIM models by Web Graphic Library (WebGL) in the context of HTML5 and JavaScript [63].

The third step is to present the calculated results on a web page to support the decision making on building fabric maintenance planning. Through the data calculations at the second 
step, different costs and optimum maintenance interval that is calculated according to $\mathrm{CM} / \mathrm{PM}$ ratio function and parameters provided by the SQL database can be determined to provide key information for the preliminary maintenance plan for the selected building fabric components. Meanwhile, the 3D visualization of the BIM model and the animation of the maintenance schedule can be implemented under the support of WebGL [63].

After the feasibility and reliability of the maintenance plan are validated through the sensitivity analysis, if the result of the analysis is positive and further accepted by building owners and managers, the information of the accepted plan would be stored as empirical data for updating the SQL database. Similarly, any adjustment or correction based on the current maintenance plan will be processed as feedback to the collection of empirical data, which would be stored into the SQL database in order to ensure timeliness and accuracy of relevant building maintenance information.

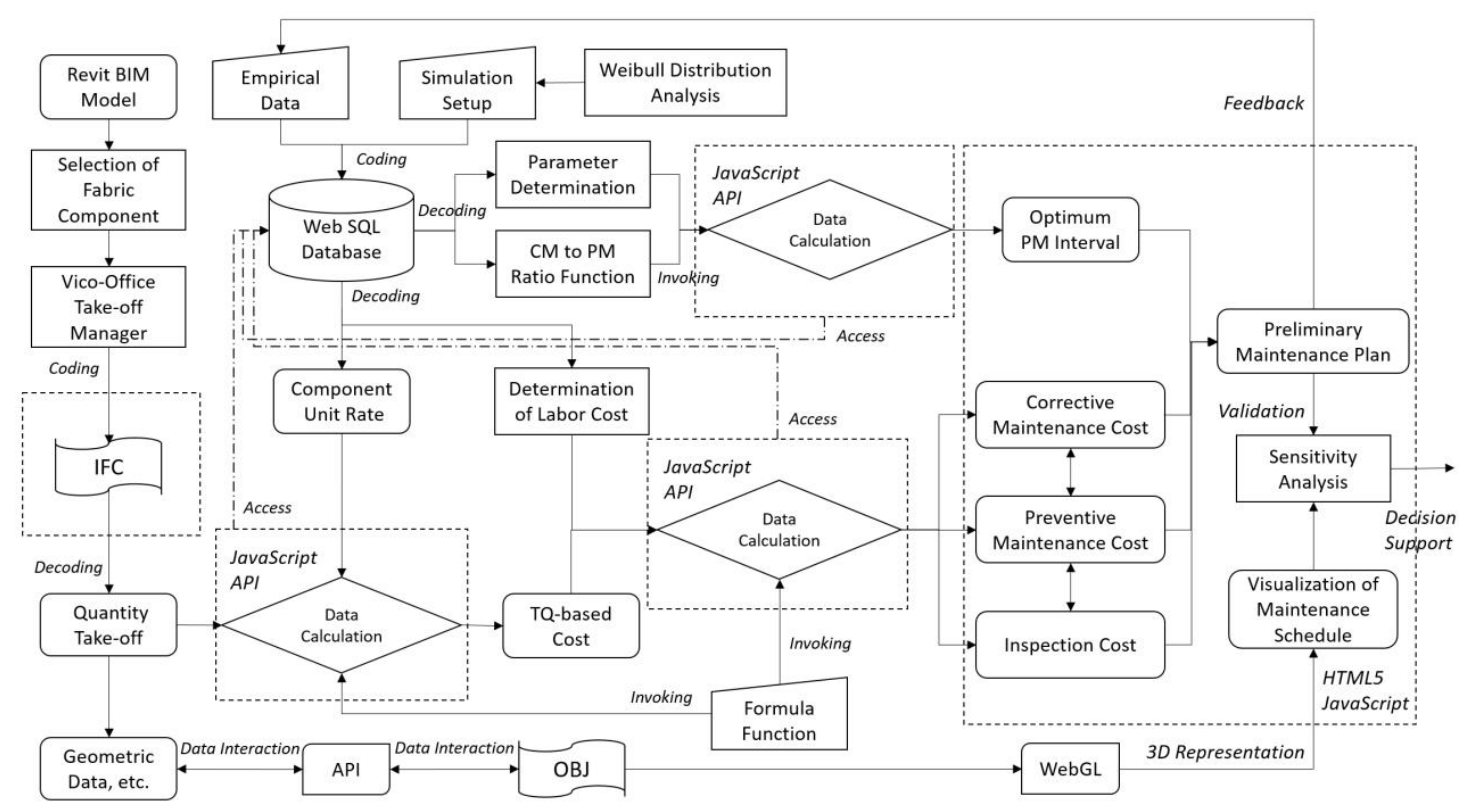

Fig.3. Design of BIM-Based Integrated Data Management Workflow

\section{Panel prototype}

Based on the design of the developed integrated data management workflow, a web-based panel prototype was generated in order to apply the management workflow into practical 
applications of building fabric maintenance. The operation interface of the panel prototype is introduced by using several screenshots, which intuitively shows the selection of model fabric components (Fig.4), calculation of specific maintenance cost (Fig.5), calculation of optimum preventive maintenance interval (Fig.6) and sensitivity analysis (Fig.7) under a semi-automatic pattern for practical use.

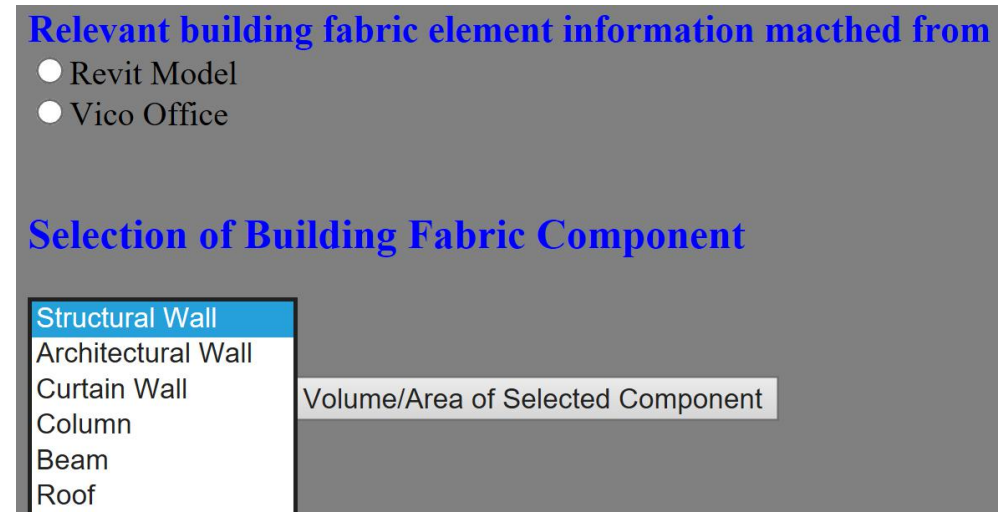

Fig.4. Operation Interface of Panel Prototype (1)

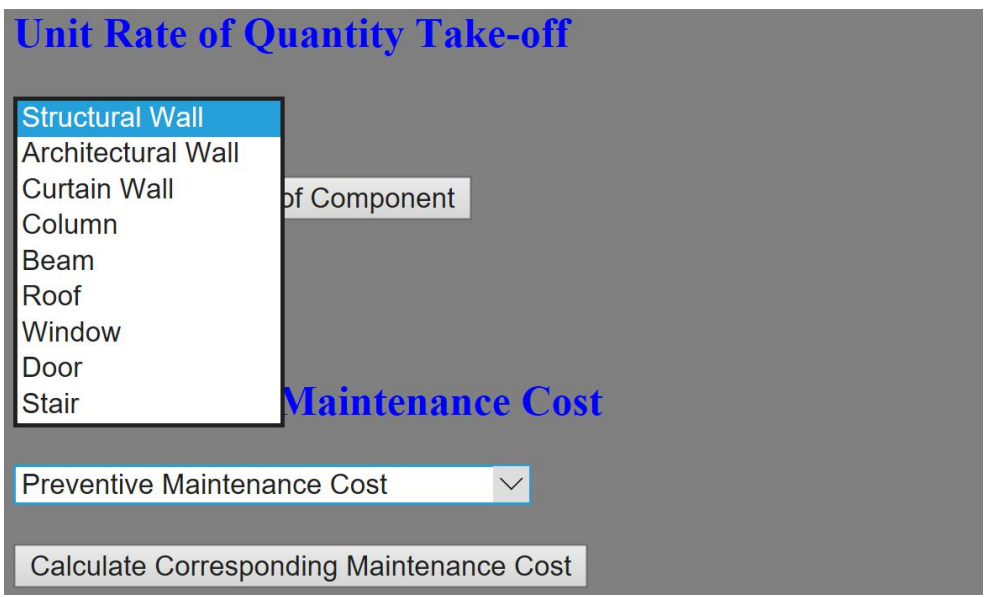

Fig.5. Operation Interface of Panel Prototype (2) 


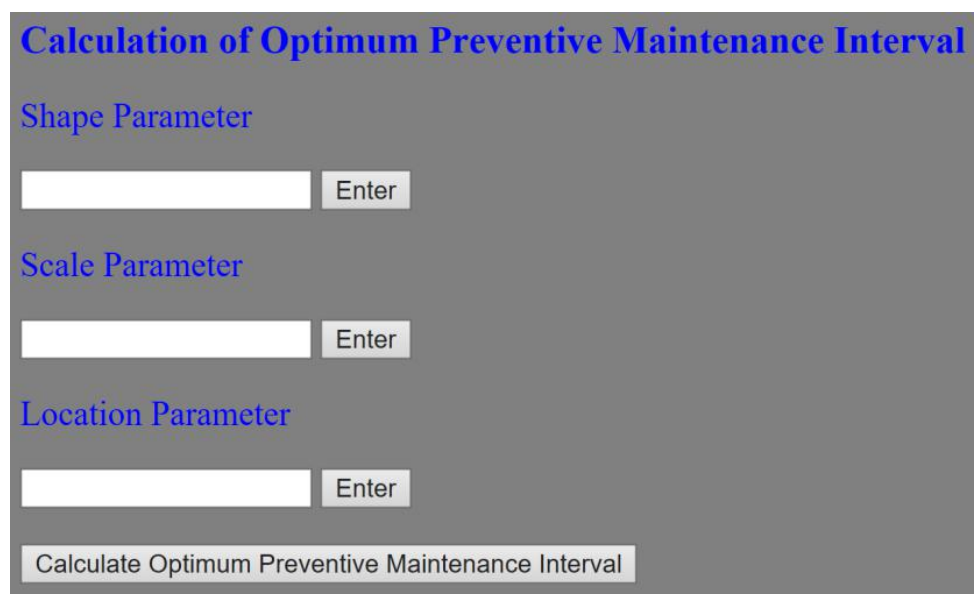

Fig.6. Operation Interface of Panel Prototype (3)

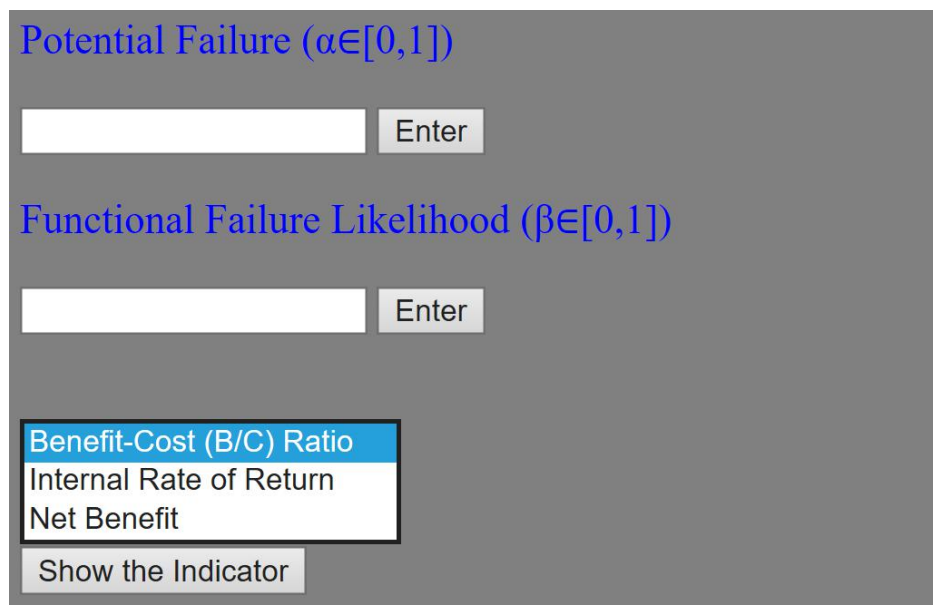

Fig.7. Operation Interface of Panel Prototype (4)

\section{Case study}

To validate the reliability of the management workflow and the feasibility of the panel prototype based on it, a case study in China was adopted for this purpose. The case is a four-floor teaching building located on the campus building of the university. This building is mainly used for teaching, training and laboratory activities of science and engineering. There are two main reasons why this building was chosen for this study. The first reason is that the building has been built for nearly six years, due to ageing and deterioration issues, the maintenance management of the building fabric components has become a challenge. Therefore, it provides an opportunity for us to validate the developed management workflow for schedule and cost planning of building fabric maintenance in practice. The second reason 
is all key information about the architectural and structural drawings of this building is retained, and this provides prerequisites for creating an accurate BIM model for the building.

As there are multiple fabric components in the building, for the specific study purpose, the curtain walls, which are located in the western and eastern facades from the ground floor to the third floor of the building atrium (as shown in Fig.8), were chosen as the maintenance fabric components due to the more frequent preventive maintenance work required than other fabric components. Furthermore, it can be seen from Fig.8 that some of the curtain walls have maintenance issues due to ageing and deterioration. Therefore, corrective maintenance work may be also needed soon.

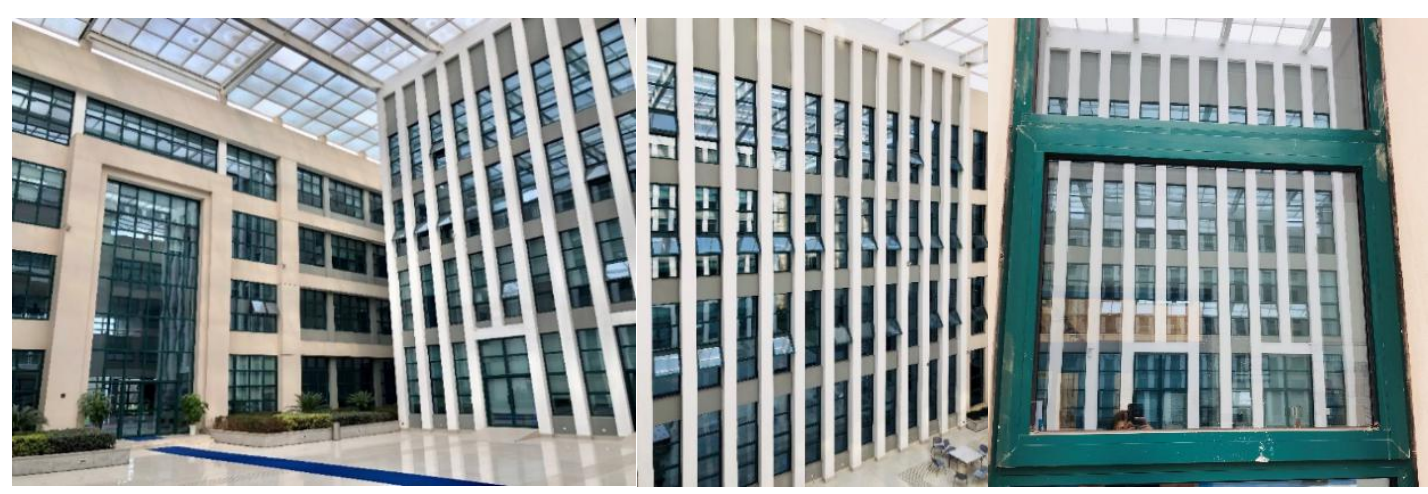

Fig.8. Maintenance Curtain Walls of the Building Atrium in Western and Eastern Facades

Based on architectural and structural drawings of the building atrium, a 3D BIM model consisting of the atrium facades and curtain walls was built in Revit as shown in Fig.9. This BIM model was initially created for visualization purpose in the design phase. Then the BIM model was converted into an IFC-based system and its 3D presentation by IFC is shown in Fig.10. The detailed component information of the curtain walls was stored in the SQL database by tables. Table 4 shows the parameters of Weibull Distribution for multiple fabric components of the atrium. Table 5 indicates detailed information for maintenance curtain walls including locations, materials, quantity take-off, unit rates and labor costs, which were initially used for quantity surveying and task planning during the construction phase. Particularly the information of quantity take-off is obtained from the estimation result in Vico Office and then stored into the database. 


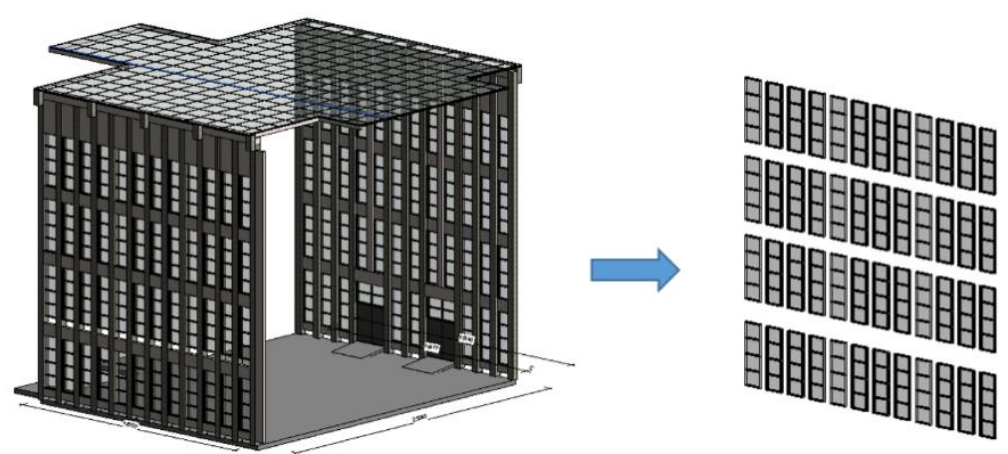

Fig.9. BIM Model of Atrium Facades and Curtain Walls
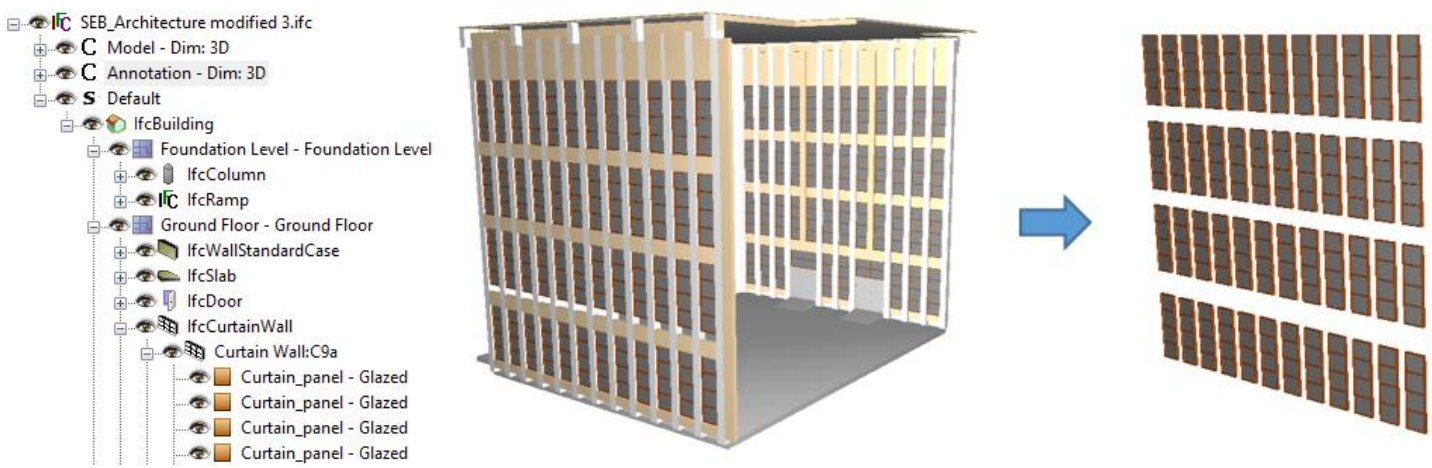

Fig.10. IFC-Based Building Component System and 3D Presentation of Curtain Walls

Table 4. "Building Fabric Component" Table for SQL Database (Part)

\begin{tabular}{|c|c|c|c|c|c|c|}
\hline $\begin{array}{c}\text { Component } \\
\text { ID }\end{array}$ & Component & Unit & $\begin{array}{c}\text { Shape } \\
\text { Parameter }\end{array}$ & $\begin{array}{c}\text { Scale } \\
\text { Parameter }\end{array}$ & $\begin{array}{c}\text { Location } \\
\text { Parameter }\end{array}$ & CM/PM \\
\hline 0001 & Structural Wall & $\mathrm{m}^{3}$ & 2 & 60 & 20 & 3.5 \\
\hline 0002 & Architectural Wall & $\mathrm{m}^{3}$ & 2 & 60 & 20 & 3.5 \\
\hline 0003 & Curtain Wall & $\mathrm{m}^{2}$ & 2.5 & 30 & 10 & 4 \\
\hline 0004 & Column & $\mathrm{m}^{3}$ & 5 & 50 & 20 & 4 \\
\hline 0005 & Beam & $\mathrm{m}^{3}$ & 5 & 50 & 20 & 4 \\
\hline
\end{tabular}

Table 5. "Curtain Wall Component" Table for SQL Database (Part)

\begin{tabular}{|c|c|c|c|c|c|c|c|}
\hline ID & Component & Location & Material & QT & Unit & Unit Rate & Labor Cost \\
\hline CW001 & Curtain Wall & $\begin{array}{c}\text { First Level } \\
\text { West 1 }\end{array}$ & $\begin{array}{c}\text { Double Glazing, } \\
\text { Stainless Steel } \\
\text { Frame }\end{array}$ & 3.57 & $\mathrm{~m}^{2}$ & 135 & 45 \\
\hline CW002 & Curtain Wall & $\begin{array}{c}\text { First Level } \\
\text { West 2 }\end{array}$ & $\begin{array}{c}\text { Double Glazing, } \\
\text { Stainless Steel } \\
\text { Frame }\end{array}$ & 3.57 & $\mathrm{~m}^{2}$ & 135 & 45 \\
\hline
\end{tabular}




\begin{tabular}{|c|c|c|c|c|c|c|c|}
\hline CW003 & Curtain Wall & $\begin{array}{c}\text { First Level } \\
\text { West 3 }\end{array}$ & $\begin{array}{c}\text { Double Glazing, } \\
\text { Stainless Steel } \\
\text { Frame }\end{array}$ & 3.57 & $\mathrm{~m}^{2}$ & 135 & 45 \\
\hline CW004 & Curtain Wall & $\begin{array}{c}\text { First Level } \\
\text { West 4 }\end{array}$ & $\begin{array}{c}\text { Double Glazing, } \\
\text { Stainless Steel } \\
\text { Frame }\end{array}$ & 3.57 & $\mathrm{~m}^{2}$ & 135 & 45 \\
\hline CW005 & Curtain Wall & $\begin{array}{c}\text { Second Level } \\
\text { West 1 }\end{array}$ & $\begin{array}{c}\text { Double Glazing, } \\
\text { Stainless Steel } \\
\text { Frame }\end{array}$ & 3.57 & $\mathrm{~m}^{2}$ & 135 & 45 \\
\hline
\end{tabular}

\section{Validation}

For comparison, manual calculations were also conducted in this study to validate the results obtained from the automatic calculations of the panel prototype based on the BIM-based workflow. It was assumed that all curtain walls in the western and eastern facades required maintenance. Therefore, by using the formulas mentioned above and the component details from the BIM model, the maintenance information of the curtain walls in both atrium facades was determined by manual calculation and shown in Table 6 .

Table 6. Maintenance Information of Curtain Walls in Western and Eastern Atrium Facades

\begin{tabular}{|l|c|c|}
\hline Maintenance characteristics & Western facade & Eastern facade \\
\hline Fabric component & curtain wall & curtain wall \\
\hline Material & double-glazing & 46 \\
\hline Number of curtain walls & 48 & 164.22 \\
\hline Area (m²) & 171.36 & $22,169.7$ \\
\hline Material cost for replacement (RMB $¥)$ & $23,133.6$ & $7,389.9$ \\
\hline Labor cost for replacement (RMB ¥) & $7,711.2$ & 29559.6 \\
\hline Corrective maintenance cost (RMB $¥)$ & $30,844.8$ & $7,392.2$ \\
\hline Preventive maintenance cost (RMB $¥ /$ per time) & $7,713.6$ & $5,915.6$ \\
\hline Inspection cost (RMB ¥ /per time) & $6,172.8$ & 26.65 \\
\hline Optimum preventive maintenance interval (week) & 26.65 & 538.2 \\
\hline Cost per unit time (RMB ¥ /per week) & 561.6 & \\
\hline
\end{tabular}


Expected replacement cycle length (week)

Furthermore, the sensitivity analysis result was also determined by assuming $\alpha$ for curtain walls equaling 0.5 (30 detections of potential failures from total 60 maintenance inspections) and $\beta$ equaling 0.75 , which was decided from the empiricism of maintenance practitioners on campus. By using the results from the manual calculations, the $\mathrm{B} / \mathrm{C}$ ratio for curtain wall maintenance was determined as 1.15 , which means the benefit will be larger than the cost if such a maintenance plan is implemented in practice.

Automatic calculations based on the developed panel prototype then were also conducted to check whether discrepancies were existing between the manual method and the BIM-based workflow method. Using the curtain walls in the western façade as an instance, some calculation results from the panel prototype are shown in Fig.11, Fig.12 and Fig.13. It can be seen that the result values generated by panel prototype are equal to the result values obtained from manual calculations. In addition, the panel also provides a BIM-based schedule simulation based on the optimum preventive maintenance interval. Fig.14 shows a screenshot of the simulation options for maintenance work execution sequence. For example, an execution sequence from the ground floor to the top third floor was selected for maintenance work on all curtain walls in the western façade. Owners and users can supervise the maintenance schedule planning from the BIM-based simulation and check the payment efficiency of cost flow after executions of maintenance work, as shown in Fig.16. According to the determined optimum preventive maintenance interval (26.65 weeks) and replacement cycle length (4.37 weeks), the maintenance work for the curtain walls in the western façade started from Week 27 and was completed by the end of Week 30 . 


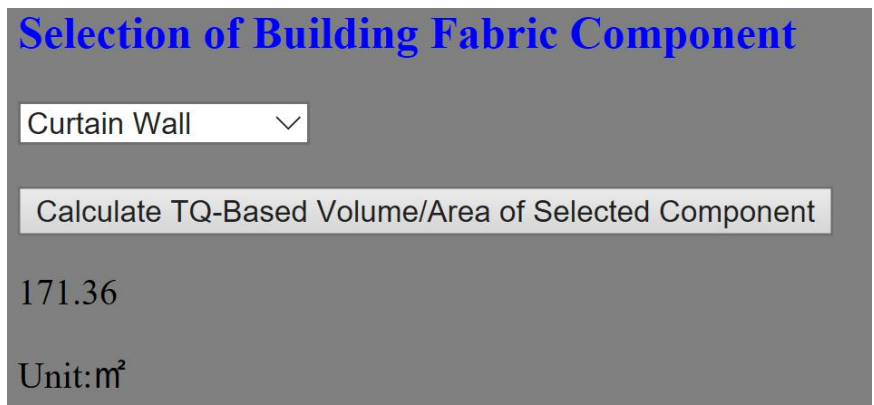

Fig.11. Quantity Take-off of Curtain Walls in the Western Facade

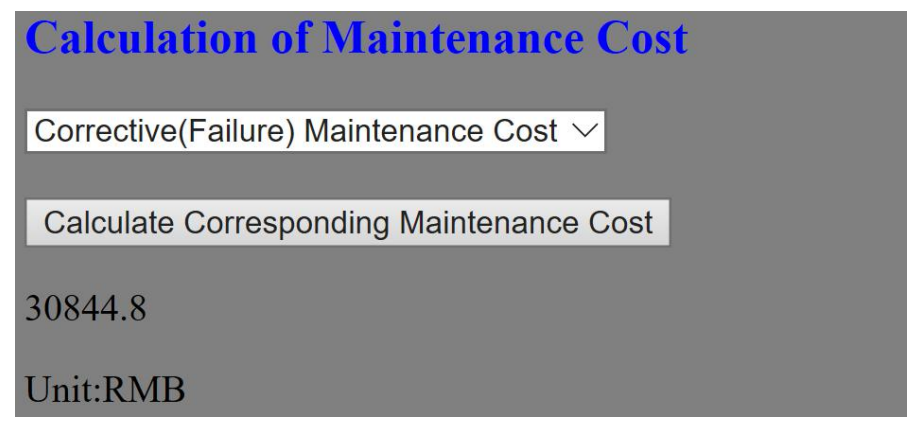

Fig.12. Corrective maintenance cost of curtain walls in the western facade

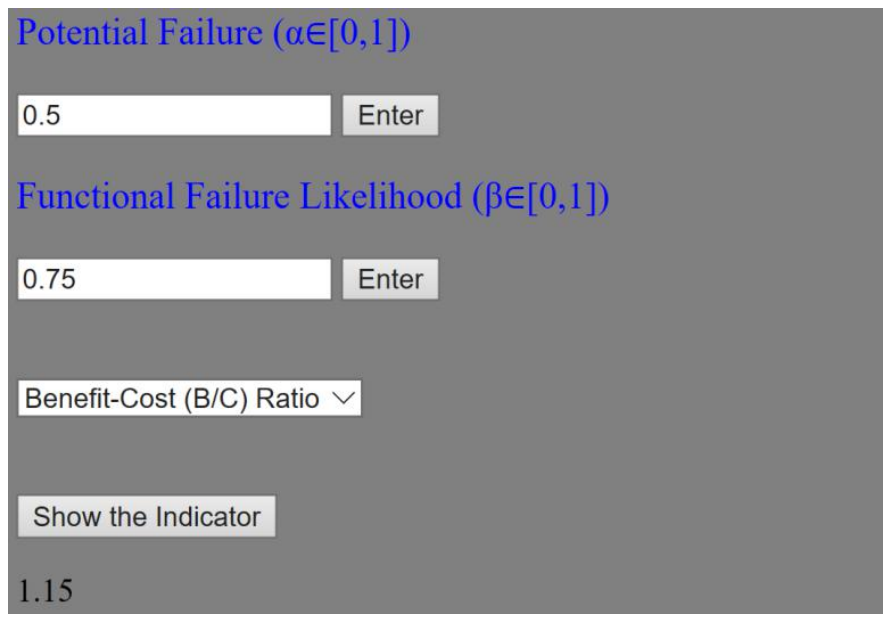

Fig.13. Calculation result of sensitivity analysis 


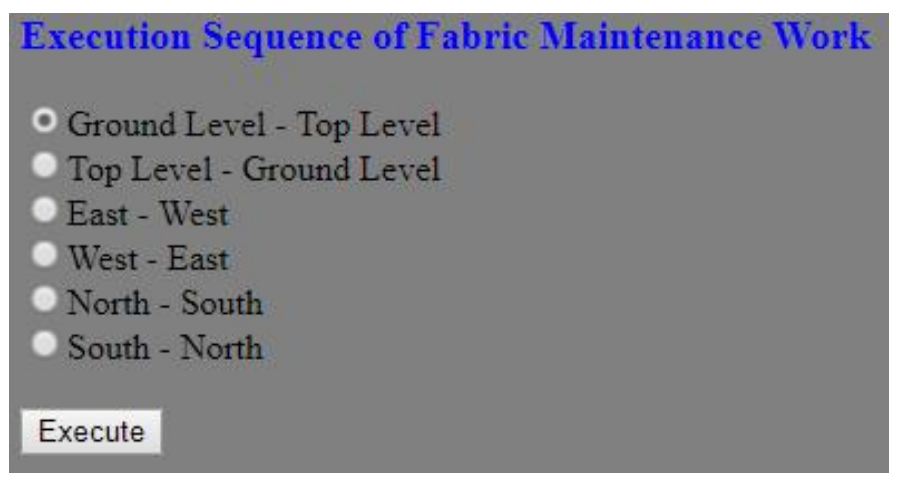

Fig.14. Simulation of different maintenance execution sequences

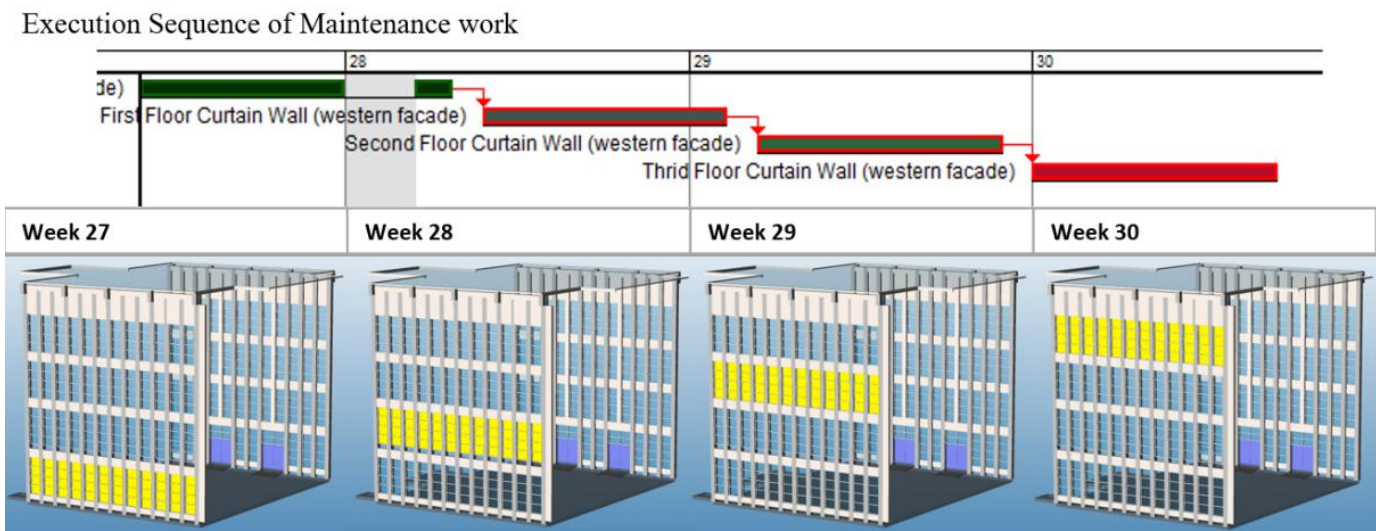

Fig.15. BIM-based simulation of maintenance schedule planning

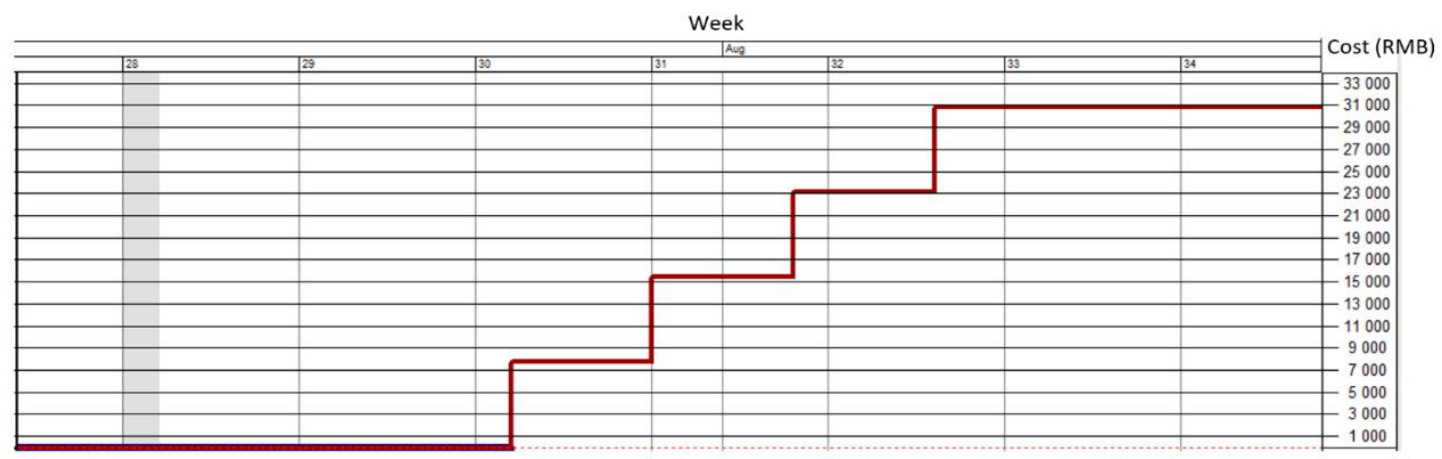

Fig.16. Estimation of payment cost flow after maintenance work

\section{Limitation \& Outlook}

The result from the case study indicates that the accuracy and reliability of the developed panel prototype have been validated. That also means the feasibility of the BIM-based integrated data management workflow has been preliminarily approved in practice. However, 
there are still some technical limitations for the current study.

First, although the BIM-based workflow shows automatic processing characteristics in data calculations, file format transformations and planning simulations, the overall information flow still requires much manual work involved such as collections of empirical data, entries of building fabric details, creations of data tables and invoking of formula functions. Second, the IFC format is not yet fully developed to ensure successful data interaction between heterogeneous systems at all times. That means risks of data inconsistency or information loss exist during the model transformations between heterogeneous software systems. Also, due to the high probabilities of uncertainties occurring in the maintenance stage, there would be discrepancies between the real maintenance performance and the BIM-based planning in schedule and costs. Therefore, more empirical data from real maintenance projects are required in order to optimize the schedule and cost planning based on the management workflow and minimize the discrepancies between theories and practice.

To reduce the technical limitations, artificial intelligence (AI) technology is proposed to be integrated with the BIM-based workflow for improving the automation level of data processing and analysis, meanwhile reducing potential errors from manual work. Furthermore, the IFC format can be extended and further developed to improve the data consistency between heterogeneous software systems. Besides, 3D imaging technologies such as laser scanning also can be integrated with BIM to implement reality captures of building fabric components in the construction phase. This can provide sufficient data to support the implementations of maintenance planning and forecast in the O\&M phase. By this way, the design and construction phase is coherently linked with the O\&M phase at an early stage to reduce the potential wastes and excessive consumption caused by later building maintenance work.

Moreover, dynamic monitoring of building fabric components can be implemented by using specific sensors, which can send periodic feedback information to the back-end database for lifecycle management purpose. Such feedback information also can be stored as empirical data for optimizations of schedule and cost planning in order to meet the construction and 
maintenance requirements. Therefore, through the integrations of BIM with advanced digital technologies, the automation of modern construction project management can be realized to highly improve the productivity and control the wastes and resource consumptions.

\section{Conclusion}

This study introduces an innovative workflow design which integrates BIM with empirical theories for schedule and cost planning of building fabric maintenance. Based on the workflow, a panel prototype also has been developed by programming and database in order to validate the feasibility of the workflow in practice. Therefore, a typical case study was conducted for the validation and the result preliminarily approved the reliability of the panel prototype and the feasibility of the BIM-based workflow. The outcome of this study not only implement the idea of narrowing the knowledge gap between maintenance theories and practical maintenance applications by a consistent and sustainable information flow based on BIM, but also link the maintenance stage with the design and construction phase which BIM is mainly applied for exploring the potential BIM value in the O\&M phase. Although some technical limitations are still existing in the current study, they will be overcome in further relevant studies soon. By that time, the facility management performance and maintenance efficiency during the O\&M phase will be highly improved to meet the requirements of sustainable development in the construction industry.

\section{Acknowledgement}

The work presented in this research study was undertaken under the aegis of the BIM-GIS Application in Green Built Environment Project, funded by the Ningbo Science and Technology Bureau (2015B11011).

\section{Disclosure Statement}

No potential conflict of interest was reported by the authors. 


\section{Data Availability Statements}

Data generated or analyzed during the study are available from the corresponding author by request.

\section{References}

[1] M.N. Grussing, L.R. Marrano, Building Component Lifecycle Repair/Replacement Model for Institutional Facility Management, ASCE International Workshop on Computing in Civil Engineering 2007, Pittsburgh, Pennsylvania, USA, July 24-27 2007.

[2] S. Lavy-Leibovich, I.M. Shohet, Integrated maintenance management of hospital buildings: a case study, Construction Management and Economics 22 (1) (2004) 25-34, DOI: 10.1080/0144619042000186031.

[3] D. Arditi, M. Nawakorawit, Designing Buildings for Maintenance: Designers' Perspective, Journal of Architectural Engineering 5 (4) (2002) 107-116, DOI: 10.1061/(ASCE)1076-0431(1999)5:4(107).

[4] A.L. Olanrewaju, A. Idrus, M.F. Khamidi, Investigating building maintenance practices in Malaysia: A case study, Structural Survey 29 (5) (2011) 397-410, DOI: $10.1108 / 02630801111182420$.

[5] B. Chanter, P. Swallow, Building Maintenance Management, 2nd Edition, Blackwell Publishing, John Wiley \& Sons, Ltd., New York, 2007, ISBN: 9781405135061.

[6] Y.M. Dessouky, A. Bayer, A simulation and design of experiments modeling approach to minimize building maintenance costs, Computers \& Industrial Engineering 43 (3) (2002) 423-436, DOI: 10.1016/s0360-8352(02)00056-6.

[7] C.S. King, C. Langendoen, L.H. Hummel, Successful On-Site Manager. Institute of Real Estate Management of the National Association, Chicago, 1984, ISBN: 9780912104621.

[8] O.O. Ajayi, J. Feranmi, O.A. Adenuga, Prevalence of Factors Affecting Maintenance Management of Prison Facilities in South-West, Ngeria, International Research Conference 2017: Shaping Tomorrow' s Built Environment Conference Proceedings, September 11-12 
2017, 220-229, International Council for Research and Innovation in Building and Construction, (Available from) http://ir.unilag.edu.ng:8080/xmlui/handle/123456789/2957 (accessed on 22 December 2018).

[9] H. Lind, H. Muyingo, Building maintenance strategies: planning under uncertainty, Property Management 30 (1) (2012) 14-28, DOI: 10.1108/02637471211198152.

[10] R. Talib, A.G. Ahmad, N. Zakaria, M.Z. Sulieman, Assessment of Factors Affecting Building Maintenance and Defects of Public Buildings in Penang, Malaysia, Architecture Research 4 (2) (2014) 48-53, DOI: 10.5923/j.arch.20140402.03.

[11] D.U. Kini, 1999, Materials management: The key to successful project management, Journal of Management in Engineering 15 (1) (1999) 30-34, DOI: 10.1061/(ASCE)0742-597X(1999)15:1(30).

[12] K.C. Iyer, K.N. Jha, Factors affecting cost performance: Evidence from Indian construction projects, International Journal of Project Management 23 (4) (2005) 283-295, DOI: 10.1016/j.ijproman.2004.10.003.

[13] E. Koehn, G. Brown, Climatic effects on construction, Journal of Construction Engineering and Management 111 (2) (1985) 129-137, DOI: 10.1061/(ASCE)0733-9364(1985)111:2(129).

[14] H.R. Thomas, A.S. Sakarcan, Forecasting labor productivity using the factor model, Journal of Construction Engineering and Management 120 (1) (1994) 228-239, DOI: 10.1061/(ASCE)0733-9364(1994)120:1(228).

[15] C. Eastman, P. Teicholz, R. Sacks, K. Liston, BIM Handbook: A Guide to Building Information Modelling For Owners, Managers, Designers, Engineers, and Contractors, Wiley Publishing, John Wiley \& Sons, Ltd., New York, 2008, ISBN: 9780470185285.

[16] D. Kehily, J. Underwood, Embedding Life Cycle Costing in 5D BIM, Journal of Information Technology in Construction 22 (2017) 145-167. http://www.itcon.org/2017/8.

[17] J. Park, H. Cai, WBS-based dynamic multi-dimensional BIM database for total construction as-built documentation, Automation in Construction 77 (2017) 15-23, DOI: 10.1016/j.autcon.2017.01.021.

[18] British Standards, BS: 3811-1984 Glossary of maintenance management terms in terotechnology, British Standards Institute, Her Majesty's Stationery Ofc., London, 1984. 
(Available from) https://shop.bsigroup.com/en/ProductDetail/?pid=000000000010071171 (accessed on 12 February 2019).

[19] R. Lee, Building Maintenance Management, Blackwell Publishing, John Wiley \& Sons Inc., Oxford, 1987, ISBN: 9780632023424.

[20] A.C. Marquez, The Maintenance Management Framework: Models and Methods for Complex Systems Maintenance, Springer Series in Reliability Engineering, Springer, London, 2007, ISBN: 9781849966542.

[20] BPG, The BPG Building Fabric Component Life Manual, CRC Press, Taylor \& Francis Inc., Cleveland, Ohio, 1999, ISBN: 9780419254805.

[21] J.S. Foster, R. Greeno, Mitchell's Structure and Fabric, Part 1 7th Edition, Routledge, Taylor \& Francis Inc., New York, 2006, ISBN: 9780131970946.

[22] E. Wang, P. Tang, Y. Wang, J. Dou, Investigation and analysis of existing building use and maintenance, Proceedings of the 2011 2nd International Conference on Mechanic Automation and Control Engineering, Hohhot, China, July 15-17 2011, DOI: 10.1109/MACE.2011.5987433.

[24] E.D. Mills, Building Maintenance and Preservation - A guide to design and management, Butterworth Heinemann Press, London, 1980, ISBN: 9780408004701.

[25] H.I. Seeley, Building Maintenance, Macmillan Press Ltd., Palgrave, London, 1976, ISBN: 9780333171608 .

[26] R. Kirkham, Ferry and Brandon's Cost Planning of Buildings 9th Edition, Blackwell Science, John Wiley \& Sons, Ltd., Chichester, West Sussex, 2015, ISBN: 9781119968627.

[27] A. Al-Hajj, M.W. Horner, Modelling the Running Costs of Buildings, Construction Management and Economics 16 (4) (1998) 459-470, DOI: 10.1080/014461998372231.

[28] H. Krstić, S. Marenjak, Maintenance and operation costs model for university buildings, Technical Gazette 24 (1) (2017) 193-200, DOI: 10.17559/TV-20140606093626.

[28] L. Ding, Y. Zhou, B. Akinci, Building Information Modeling (BIM) application framework: The process of expanding from $3 \mathrm{D}$ to computable $\mathrm{nD}$, Automation in Construction 46 (2014) 82-93, DOI: 10.1016/j.autcon.2014.04.009.

[29] F. Gloud, N. Joyce, Construction Project Management, 4/E, Pearson Education Inc., Antonio, 2014, ISBN: 9780132877244. 
[31] W. Shou, J. Wang, X. Wang, H.Y. Chong, A comparative review of building information modelling implementation in building and infrastructure industries, Archives of Computational Methods in Engineering 22 (2) (2015) 291-308, DOI: $10.1007 / \mathrm{s} 11831-014-9125-9$.

[32] W.C. Shou, J. Wang, X.Y. Wang, 4D BIM for Improving Plant Turnaround Maintenance Planning and Execution: A Case Study, 35th International Symposium on Automation and Robotics in Construction (ISARC 2018), Berlin, Germany, July 20-25 2018.

[33] D. Mitchell, 5D - Creating Cost Certainty and Better Buildings, RICS COBRA Conference, Las Vegas, Nevada, USA, September 11-13 2012.

[34] X. Jiang, Research on Application of BIM 5D Technology in Central Grand Project, Procedia Engineering 174 (2017) 600-610, DOI: 10.1016/j.proeng.2017.01.194.

[35] A.K. Nicał, W. Wodyński, Enhancing Facility Management through BIM 6D, Procedia Engineering 164 (2016) 299-306, DOI: 10.1016/j.proeng.2016.11.623.

[36] Z. Pučko, N. Šuman, U. Klanšek, Building Information Modeling Based Time And Cost Planning In Construction Projects, Organization, Technology \& Management in Construction: An International Journal 6 (1) (2014) 958-971, DOI: .10.5592/otmcj.2014.1.6

[37] O.A. Olatunji, W. Sher, N. Gu, Building information modeling and quantity surveying practice, Emirates Journal for Engineering Research 15 (1) (2010) 67 -70, DOI: 10.1016/j.peva.2011.09.002.

[38] M. Frei, J. Mbachu, R. Phipps, Critical success factors, opportunities and threats of the cost management profession: the case of Australasian quantity surveying firms, International Journal of Project Organisation and Management 5 (1/2) (2013) 4-24, DOI: 10.1504/IJPOM.2013.053151.

[39] P. Smith, Project Cost Management with 5D BIM, Procedia - Social and Behavioral Sciences 226 (2016) 193-200, DOI: 10.1016/j.sbspro.2016.06.179.

[40] Q. Lu, J. Won, J.C.P. Cheng, A financial decision making framework for construction projects based on 5D Building Information Modeling (BIM), International Journal of Project Management 34 (1) (2016) 3-21, DOI: 10.1016/j.ijproman.2015.09.004.

[41] Z. Pučko, D. Vincek, A. Štrukelj, N. Šuman, Application of 6D Building Information Model (6D BIM) for Business-storage Building in Slovenia, IOP Conference Series: 
Materials Science and Engineering 245 (2017) 062028, DOI: $10.1088 / 1757-899 \mathrm{X} / 245 / 6 / 062028$.

[42] Q. Lu, L. Chen, S. Lee, X. Zhao, Activity theory-based analysis of BIM implementation in building O\&M and first response, Automation in Construction 85 (2018) 317-332, DOI: 10.1016/j.autcon.2017.10.017

[43] B. Dodson, The Weibull Analysis Handbook, Second Edition, ASQC, Quality Press, Milwaukee, Wisconsin, 1994, ISBN: 9780873896672.

[44] W. Weibull, A Statistical Distribution Function of Wide Applicability, Journal of Applied Mechanics 18 (1951) 293-297, DOI: 10.1093/qjmam/6.4.453.

[45] C.J. Hopfe, Uncertainty and sensitivity analysis in building performance simulation for decision support and design optimization, Eindhoven University Press, Eindhoven, 2009, ISBN: 9789068146172. DOI: 10.6100/IR643321.

[46] S. Saraneva, Warranty prediction using Weibull simulation, (Available from) http://urn.fi/URN:NBN:fi-fe2014082133000 (accessed 12 December 2018).

[47] B. Dodson, Determining the Optimum Schedule for Preventive Maintenance, Quality Engineering 6 (4) (1994) 667-679, DOI: 10.1080/08982119408918757.

[48] B. Dodson, D. Nolan, Reliability Engineering Handbook, Quality Publishing Co., Hamilton, Ohio, 2002, ISBN: 9780930011857.

[49] A.K.S. Jardine, A.H.C. Tsang, Maintenance, Replacement and Reliability: Theory and Applications, Second Edition, CRC Press, Taylor \& Francis Inc., Cleveland, Ohio, 2013, ISBN: 9781466554856.

[50] M. Fajardo, L.V. Ortiz, Analysis of the Preventive/Corrective Maintenance Ratio for DDG class ships, Naval Postgraduate School, Monterey, California, USA, 2011, (Available from) http://hdl.handle.net/10945/5722 (accessed on 16 February 2019).

[51] C. Stenström, P. Norrbin, A. Parida, U. Kumar, Preventive and corrective maintenance cost comparison and cost-benefit analysis, Structure and Infrastructure Engineering 12 (5) (2016) 603-617, DOI: 10.1080/15732479.2015.1032983.

[52] I. Ofori, P.M. Duodu, S.O. Bonney, Establishing Factors Influencing Building Maintenance Practices: Ghanaian Perspective, Journal of Economics and Sustainable 
https://iiste.org/Journals/index.php/JEDS/article/view/27920 (accessed on 10 January 2019).

[53] A. Nikakhtar, A.A. Hosseini, K.Y. Wong, Sensitivity Analysis of Construction Processes Using Computer Simulation: A Case Study, Advanced Science Letters 13 (1) (2012) 680-684, DOI: $10.1166 / a s 1.2012 .3923$.

[54] Trimble, BIM Solutions - Vico Office, (Available from) https://gc.trimble.com/product-categories/bim-solutions (accessed December 20, 2018).

[55] J. Chen, K.C. Clarke, Modeling Standards and File Formats for Indoor Mapping, Proceedings of the 3rd International Conference on Geographical Information Systems Theory, Applications and Management, Porto, Portugal, April 27-28 2017, Vol. 1: GISTAM, pp. 268-275, SciTePress, DOI:10.5220/0006364202680275.

[56] C. Fu, G. Aouad, A.J.M. Ponting, A. Lee, S. Wu, IFC implementation in lifecycle costing, Journal of Harbin Institute of Technology 11 (4) (2004) 437-441, (Available from) http://usir.salford.ac.uk/612/ (accessed on 25 January 2019).

[57] Dassault System, Architecture, Engineering \& Construction: End-to-end Collaboration Enabled by BIM Level 3, (Available from) https://www.docin.com/p-1726924998.html (accessed on 10 February 2019).

[58] J. Eynon, Digital Built Britain BIM Level 3 Strategy, Construction Manager's BIM Handbook, 1st Edition, John Wiley \& Sons, Ltd., Chichester, West Sussex, 2016, ISBN: 9781119163404.

[59] K. Mensah, Oracle Database Programming Using Java and Web Services, Elsevier Digital Press, Newton, MA, 2005, ISBN: 9781555583293.

[60] W3C, HTML 5.3 Editor's Draft, World Wide Web Consortium, (Available from) https://dev.w3.org/html5/ (accessed on 10 February 2019).

[61] R.T. Gutiérrez, Understanding the role of digital commons in the web; The making of HTML5, Telematics and Informatics 35 (5) (2018) 1438-1449, DOI: 10.1016/j.tele.2018.03.013.

[62] D. Flanagan, JavaScript: The Definitive Guide, 6th Edition, O'Reilly Media, Massachusetts, 2011, ISBN: 9780596805524.

[63] J.Y. Xia, B.J. Xiao, D. Li, K.R. Wang, Interactive WebGL-based 3D visualizations for EAST experiment, Fusion Engineering and Design 112 (2016) 946-951, DOI: 
10.1016/j.fusengdes.2016.04.006. 